\title{
Health-Related Quality of Life in Adult Survivors of Childhood Wilms Tumor or Neuroblastoma: A Report From the Childhood Cancer Survivor Study
}

\author{
Paul C. Nathan, MD, MSc, ${ }^{1}$ Kirsten K. Ness, PT, PhD, ${ }^{2}$ Mark L. Greenberg, MB, ChB, ${ }^{1}$ Melissa Hudson, $\mathrm{MD}^{3}$ \\ Suzanne Wolden, $\mathrm{MD}^{4}{ }^{4}$ Andrew Davidoff, $\mathrm{MD}^{3}$ Caroline Laverdiere, $\mathrm{MD}^{5}{ }^{5}$ Ann Mertens, $\mathrm{PhD}^{2}{ }^{2}$ \\ John Whitton, $\mathrm{MS}^{6}{ }^{6}$ Leslie L. Robison, PhD, ${ }^{3}$ Lonnie Zeltzer, $\mathrm{MD}^{7}{ }^{7}$ and James G. Gurney, $\mathrm{PhD}^{8}$
}

\begin{abstract}
Background. Long-term survivors of Wilms tumor and neuroblastoma may experience significant late adverse effects from their disease and its therapy. Little is known, however, about the healthrelated quality of life experienced by these survivors. Procedure. Health-related quality of life, measured by the 36-Item Short Form Health Survey (SF-36), was assessed from self-report in adult survivors of Wilms tumor $(\mathrm{N}=654)$ and neuroblastoma $(\mathrm{N}=432)$ who participated in the Childhood Cancer Survivor Study. Results. More than $90 \%$ of the study population was $18-34$ years old at interview, and $58 \%$ were females. There was no significant difference on any SF-36 subscale or summary scale between the two diagnostic groups. On average, survivors reported no decrement on the Physical Component Summary scale of the SF-36 when compared to population norms. However, both groups scored
\end{abstract}

significantly below the population mean score (50) on the Mental Component Summary Scale of the SF-36 (Wilms tumor mean $=41.66$, standard error $=2.19, P<0.0001$; neuroblastoma mean $=42.41, \quad$ standard error $=2.23, \quad P<0.0001) \quad$ reflecting decreased emotional health. Independent risk factors for lower scores on this scale included female gender, Native American race, unemployment, and household income below \$20,000. Conclusions. Adult survivors of childhood Wilms tumor and neuroblastoma do not differ from population norms on most health-related quality of life (HRQL) measures. These data, however, indicate that the emotional well being of adult survivors may be compromised. Health care providers should be aware of the risk of adverse outcomes in emotional health even many years after treatment and cure. Pediatr Blood Cancer 2007;49:704-715. @ 2006 Wiley-Liss, Inc.

Key words: health-related quality of life; neuroblastoma; survivorship; Wilms tumor

\section{INTRODUCTION}

Neuroblastoma and Wilms tumor are the two most common extracranial solid tumors in children younger than age 15 years, accounting for approximately $13.6 \%$ of malignancies in the pediatric population [1]. Similarities between these tumors include their embryonal origin, a peak incidence in children younger than 5 years of age, and a predominantly abdominal presentation $(65 \%$ of neuroblastomas and all Wilms tumors) [2]. However, Wilms tumor is associated with a high rate of cure [3], while children with highrisk neuroblastoma fare poorly despite intensive therapy [4]. In Wilms tumor, the evolution of therapy has focused on achieving higher cure rates with a minimization of long-term adverse effects. Although there has been a similar focus in children with low or intermediate risk neuroblastoma, treatment of patients with highrisk disease has become increasingly intensified [5]. In prior treatment eras, children with Wilms tumor and low or intermediate risk neuroblastoma were exposed to more aggressive multimodal therapies, including radical surgery, orthovoltage radiation, and chemotherapy. Consequently, long-term survivors of low or intermediate risk neuroblastoma as well as Wilms tumor may experience significant long-term adverse effects.

Although several publications have described the long-term medical complications from Wilms tumor [6-11] and neuroblastoma [12-19], there are few studies describing the healthrelated quality of life (HRQL) of these survivors. Barr and colleagues compared HRQL between survivors of Wilms tumor (stages 2-5) and advanced neuroblastoma (stage 4 and inoperable stage 3) using the Health Utilities Index (HUI) in a cohort of 78 patients, 5 years after completion of their therapy [20]. There was no difference in mean overall HRQL utility scores between the two populations, although survivors of Wilms tumor were more likely to be assessed by their parents as having no disabilities. Survivors of neuroblastoma had a higher frequency of deficits in hearing and speech, which is consistent with the high doses of cisplatin that are typically included in treatment regimens for highrisk disease [21,22]. In another study of 19 patients receiving therapy for high-risk neuroblastoma, decrements in HRQL were noted during the period immediately following diagnosis and in the first few weeks after bone marrow transplantation [23]; however, this study did not assess long-term outcomes. The greatest morbidity was observed in the pain, self-care, mobility, and emotion domains.

The goal of the present study was to assess HRQL in long-term survivors of Wilms tumor and neuroblastoma, and to examine the sociodemographic, disease and treatment variables that influence these outcomes. We examined data from the Childhood Cancer Survivor Study (CCSS), a follow-up study of approximately 14,000

This article contains supplementary material available at www. interscience.wiley.com/jpages/1545-5009/suppmat.

${ }^{1}$ The Hospital for Sick Children, Toronto, Ontario, Canada; ${ }^{2}$ University of Minnesota Cancer Center, Minneapolis, Minnesota; ${ }^{3}$ St. Jude Children's Research Hospital, Memphis, Tennessee; ${ }^{4}$ Memorial Sloan Kettering Cancer Center, New York, New York; ${ }^{5}$ Hospital Sainte Justine, Montreal, Quebec, Canada; ${ }^{6}$ Fred Hutchison Cancer Research Center, Seattle, Washington; ${ }^{7}$ UCLA School of Medicine, Los Angeles, California; ${ }^{8}$ Department of Pediatrics, Child Health Evaluation and Research Unit, University of Michigan, Ann Arbor, Michigan

Grant sponsor: National Cancer Institute; Grant number: U24 CA55727; Grant sponsor: Children's Cancer Research Fund; Grant sponsor: Lance Armstrong Foundation; Grant number: G 00-12-07602 .

*Correspondence to: Paul C. Nathan, The Hospital for Sick Children, 555 University Avenue, Toronto, ON M5G 1X8, Canada.

E-mail: paul.nathan@ @ickkids.ca

Received 10 April 2006; Accepted 31 May 2006 
long-term survivors of pediatric cancer [24]. This cohort includes a considerably larger group of survivors of Wilms tumor and neuroblastoma and a longer period of follow-up than the abovementioned studies. Our primary a priori hypothesis was that the prevalence of adverse outcomes in HRQL would be higher in survivors of neuroblastoma than in survivors of Wilms tumor.

\section{PATIENTS AND METHODS}

\section{Childhood Cancer Survivor Study (CCSS)}

The survivors of Wilms tumor and neuroblastoma evaluated in this study are a subset of the 14,370 participants in the CCSS. The methodology of the CCSS and a description of the study participants have been published in detail previously [24]. Briefly, the CCSS is a multi-institutional study aimed at determining the late adverse outcomes following treatment for cancer during childhood or adolescence. The CCSS cohort consists of survivors of childhood cancer who were diagnosed before the age of 21 years between 1970 and 1986, and who were alive at least 5 years from their original diagnosis. At the time of study enrollment (1995-1996 for most participants), a comprehensive baseline questionnaire was completed by the participant (if aged 18 years or older) or his or her parent (if younger than age 18 years), and detailed medical information was abstracted from hospital records. Several subsequent questionnaires have been completed by the study participants, including a questionnaire on quality of life that is the basis for this analysis. The study methodology was approved by the Institutional Review Board of each of the 26 participating institutions and informed consent was obtained from each participant or his or her parent or guardian.

\section{Survivors of Wilms Tumor or Neuroblastoma}

Eligibility for this analysis of CCSS participants was limited to those diagnosed with Wilms tumor or neuroblastoma who were aged 18 years or older at the time of the CCSS follow-up questionnaire that was administered in 2002 and 2003. Information regarding HRQL and current sociodemographic status (age at interview, household income, health insurance, education, marital status, employment status) were obtained as part of this follow-up questionnaire. Baseline demographics (gender, race), disease variables (diagnosis, age at diagnosis, location of tumor in neuroblastoma patients), and treatment variables (chemotherapy including alkylating agent score and anthracycline score, surgery including history of laminectomy, laparotomy, nephrectomy or thoracotomy, and radiation field and dose) were abstracted from the CCSS database. These data were also used to determine if participants had a major medical condition. This composite measure was defined as the presence of one or more of seizures, congestive heart failure, myocardial infarction, stroke, cirrhosis, pulmonary disease requiring oxygen, solid organ transplant, second malignancy, amputation, or joint replacement [25].

\section{Measures of Health-Related Quality of Life}

HRQL was assessed with the 36-Item Short Form Health Survey (SF-36). The SF-36 is a widely used and well-validated global HRQL instrument that contains eight individual subscales representing physical, emotional, and social well being [26]. These subscales are physical function, role function-physical (assessing role limitations caused by physical factors), bodily pain, social function, mental health, role function-emotional (assessing role limitations caused by emotional factors), vitality, and general health. The SF-36 can also be scored as two summary scales, the Physical Component Summary scale (PCS) and the Mental Component Summary scale (MCS). General population norms are available for the subscales and summary scales [27]. Data are normalized and presented as $t$-scores with a normal population mean score set at 50 with a standard deviation of 10 .

\section{Statistical Analysis}

Descriptive statistics for the sociodemographic, disease and treatment variables were calculated separately for the Wilms tumor and neuroblastoma survivor groups. Means and standard deviations were calculated for the eight subscales and two summary scales of the SF-36, stratified by diagnosis, sociodemographic variables, and the presence or absence of a major medical condition. Means were compared between the two diagnostic groups and between levels of the sociodemographic variables with two sample $t$-tests. General linear regression was used to evaluate the association between diagnosis, sociodemographic variables, major medical condition, and each of the HRQL outcomes in adjusted models [28]. Results are reported as means and standard deviations with two-sided $P$-values.

To determine the diagnostic and treatment characteristics of the survivors who indicated poor HRQL, we dichotomized those patients with complete treatment data into two groups for each SF-36 subscale and summary scale. Individuals who scored lower than 40 (greater than one standard deviation below the mean) on any of the SF-36 subscales or summary scales were considered to have poor HRQL in that domain. Frequencies and percents of poor outcomes on each of the SF-36 subscales and summary scales were calculated separately for Wilms tumor and neuroblastoma survivors by diagnostic and treatment variables, and proportions were compared with Chi-squared tests. Multiple variable unconditional logistic regression was used to evaluate the magnitude of the associations between diagnostic and treatment variables and poor HRQL. Final models were selected using goodness of fit methods and by comparing Chi-squared values between full and reduced models [29]. Results are reported as adjusted odds ratios with $95 \%$ confidence intervals. SAS version 9.1 (Cary, N.C.) was used for all analyses.

\section{RESULTS}

\section{Characteristics of the Study Cohort}

A total of 1,440 patients ( 843 Wilms tumor, 597 neuroblastoma) were eligible for these analyses. Of these, 654 (77.6\%) Wilms tumor survivors and $432(72.4 \%)$ neuroblastoma survivors completed the HRQL follow-up questionnaire. The 1,086 study participants were statistically similar to the 354 eligible non-participants in terms of employment status and current health insurance, but differed significantly for several other sociodemographic characteristics. Non-participants tended to be somewhat younger than participants ( $48.9 \%$ vs. $43.0 \%$ age $18-24$ years), were more likely to be of Black race $(10.7 \%$ vs. $3.5 \%)$, were less likely to have a college degree ( $25.7 \%$ vs. $40.3 \%$ ), were more likely to be in the lowest annual 
household income category ( $14.1 \%$ vs. $9.7 \%$ with $<\$ 20,000)$, and were more likely to have a major medical condition $(12.7 \%$ vs. $8.9 \%)$. The sociodemographic characteristics of the study participants are displayed in Table I. Survivors of neuroblastoma were younger and more likely to describe themselves as "single" than were survivors of Wilms tumor.

Treatment data were available for 1,019 of the 1,086 patients who completed the HRQL follow-up questionnaire. Diagnosis and treatment characteristics of these survivors are shown in Table II. Survivors of Wilms tumor were more likely than survivors of neuroblastoma to have received either chemotherapy or radiation, to have received an anthracycline, or radiation to the abdomen or pelvis, or to have undergone a nephrectomy. In contrast, survivors of neuroblastoma were more likely than survivors of Wilms tumor to have been followed for a longer period of time from diagnosis, to have been treated with either surgery alone or surgery and radiation (compared to treatment with combined modality therapy that includ- ed chemotherapy), to have received an alkylating agent, or radiation to the head, neck or spine, or to have undergone a laminectomy or thoracotomy.

\section{HRQL Outcomes}

Adjusted mean scores on the PCS and MCS are displayed in Table III by sociodemographic variables and diagnostic category. There was no difference between the Wilms tumor and neuroblastoma survivors on either of the two summary scales. Overall, survivors who were looking for work or unable to work (compared to those employed or not seeking paid work) and those without health insurance (compared to those with health insurance) scored significantly lower on the PCS (indicating decreased HRQL due to poor physical function), while patients aged 18-24 years scored significantly higher on the PCS than those older than age 35 years. On the MCS, both the Wilms tumor $($ mean $=41.66, \mathrm{SE}=2.19)$

TABLE I. Characteristics of the Study Population

\begin{tabular}{|c|c|c|c|c|c|c|c|}
\hline & \multicolumn{2}{|c|}{ Wilms tumor } & \multicolumn{2}{|c|}{ Neuroblastoma } & \multicolumn{2}{|c|}{ Total } & \multirow[b]{3}{*}{$P$-value* } \\
\hline & \multicolumn{2}{|c|}{$\mathrm{N}=654$} & \multicolumn{2}{|c|}{$\mathrm{N}=432$} & \multicolumn{2}{|c|}{$\mathrm{N}=1,086$} & \\
\hline & $\mathrm{N}$ & $\%$ & $\mathrm{~N}$ & $\%$ & $\mathrm{~N}$ & $\%$ & \\
\hline Age group at the time of questionnaire & & & & & & & 0.007 \\
\hline $18-24$ years & 261 & $(39.9)$ & 206 & $(47.7)$ & 467 & $(43.0)$ & \\
\hline $25-34$ years & 343 & $(52.4)$ & 203 & $(47.0)$ & 546 & $(50.3)$ & \\
\hline $35+$ years & 50 & (7.6) & 23 & $(5.3)$ & 73 & $(6.7)$ & \\
\hline Gender & & & & & & & 0.94 \\
\hline Female & 383 & $(58.6)$ & 252 & $(58.3)$ & 635 & $(58.5)$ & \\
\hline Male & 271 & $(41.4)$ & 180 & $(41.7)$ & 451 & $(41.5)$ & \\
\hline Race/ethnicity & & & & & & & 0.65 \\
\hline White & 589 & $(90.1)$ & 401 & $(92.8)$ & 990 & $(91.2)$ & \\
\hline Native American & 4 & $(0.6)$ & 2 & $(0.5)$ & 6 & $(0.6)$ & \\
\hline Asian & 4 & $(0.6)$ & 6 & $(1.4)$ & 10 & $(0.9)$ & \\
\hline Black & 30 & (4.6) & 8 & $(1.9)$ & 38 & (3.5) & \\
\hline Hispanic & 25 & (3.8) & 11 & $(2.5)$ & 36 & (3.3) & \\
\hline Other & 2 & $(0.3)$ & 4 & $(0.9)$ & 6 & $(0.6)$ & \\
\hline Household income (annual) & & & & & & & 0.57 \\
\hline$<\$ 20,000$ & 63 & $(9.6)$ & 42 & $(9.7)$ & 105 & $(9.7)$ & \\
\hline$\$ 20-59,000$ & 270 & $(41.3)$ & 185 & $(42.8)$ & 455 & $(41.9)$ & \\
\hline$\$ 60-99,999$ & 163 & $(24.9)$ & 93 & $(21.5)$ & 256 & $(23.6)$ & \\
\hline$\$ 1,00,000+$ & 82 & $(12.5)$ & 44 & $(10.2)$ & 126 & $(11.6)$ & \\
\hline Unknown & 76 & $(11.6)$ & 68 & $(15.7)$ & 144 & $(13.3)$ & \\
\hline Education & & & & & & & 0.88 \\
\hline$<$ High school & 26 & $(4.0)$ & 19 & $(4.4)$ & 45 & $(4.1)$ & \\
\hline High school graduate & 362 & $(55.4)$ & 235 & $(54.4)$ & 597 & $(55.0)$ & \\
\hline College graduate & 262 & $(40.1)$ & 176 & $(40.7)$ & 438 & $(40.3)$ & \\
\hline Unknown & 4 & $(0.6)$ & 2 & $(0.5)$ & 6 & $(0.6)$ & \\
\hline Marital status & & & & & & & $<0.0001$ \\
\hline Married or living as married & 304 & $(46.5)$ & 141 & $(32.6)$ & 445 & $(41.0)$ & \\
\hline Single & 323 & $(49.4)$ & 275 & $(63.7)$ & 598 & $(55.1)$ & \\
\hline Divorced or separated & 20 & $(3.1)$ & 13 & $(3.0)$ & 33 & $(3.0)$ & \\
\hline Unknown & 7 & (1.1) & 3 & $(0.7)$ & 10 & $(0.9)$ & \\
\hline Employment & & & & & & & 0.84 \\
\hline Employed or caring for home & 445 & $(68.0)$ & 287 & $(66.4)$ & 732 & $(67.4)$ & \\
\hline Looking for work or unable to work & 64 & $(9.8)$ & 39 & $(9.0)$ & 103 & $(9.5)$ & \\
\hline Student & 145 & $(22.2)$ & 106 & $(24.5)$ & 251 & $(23.1)$ & \\
\hline Current health insurance & 573 & $(87.6)$ & 377 & $(87.3)$ & 950 & $(87.5)$ & 0.87 \\
\hline Major medical condition & 54 & $(8.3)$ & 43 & $(10.0)$ & 97 & $(8.9)$ & 0.34 \\
\hline
\end{tabular}

* $P$-value reported for Chi-squared comparison of Wilms tumor versus neuroblastoma. 
TABLE II. Diagnosis and Treatment Characteristics*

\begin{tabular}{|c|c|c|c|c|c|c|c|}
\hline & \multirow{2}{*}{\multicolumn{2}{|c|}{$\begin{array}{c}\text { Wilms tumor } \\
\mathrm{N}=612\end{array}$}} & \multirow{2}{*}{\multicolumn{2}{|c|}{$\begin{array}{c}\text { Neuroblastoma } \\
\mathrm{N}=407\end{array}$}} & \multirow{2}{*}{\multicolumn{2}{|c|}{$\begin{array}{c}\text { Total } \\
\mathrm{N}=1,019\end{array}$}} & \multirow[b]{3}{*}{$P$-value** } \\
\hline & & & & & & & \\
\hline & $\mathrm{N}$ & $\%$ & $\mathrm{~N}$ & $\%$ & $\mathrm{~N}$ & $\%$ & \\
\hline \multicolumn{8}{|l|}{ Age at diagnosis (Wilms tumor) } \\
\hline$<2$ years & 193 & $(31.5)$ & & & & & \\
\hline $2-5$ years & 334 & $(54.6)$ & & & & & \\
\hline $6+$ years & 85 & $(13.9)$ & & & & & \\
\hline \multicolumn{8}{|l|}{ Age at diagnosis (neuroblastoma) } \\
\hline$\leq 1$ year & & & 219 & $(53.8)$ & & & \\
\hline $1+$ years & & & 188 & $(46.2)$ & & & \\
\hline Survival time & & & & & & & 0.006 \\
\hline 16-20 years & 243 & $(39.7)$ & 122 & $(30.0)$ & 365 & $(35.8)$ & \\
\hline $21-25$ years & 193 & $(31.5)$ & 149 & $(36.6)$ & 342 & $(33.6)$ & \\
\hline $26-30$ years & 135 & $(22.1)$ & 96 & $(23.6)$ & 231 & $(22.7)$ & \\
\hline $31-35$ years & 41 & $(6.7)$ & 40 & $(9.8)$ & 81 & $(7.9)$ & \\
\hline \multicolumn{8}{|l|}{ Treatment modalities ${ }^{\mathrm{a}}$} \\
\hline Chemotherapy & 601 & $(98.2)$ & 237 & $(58.2)$ & 838 & $(82.2)$ & $<0.0001$ \\
\hline Radiation & 393 & $(64.2)$ & 203 & $(49.9)$ & 596 & $(58.5)$ & 0.0001 \\
\hline Surgery & 612 & $(100.0)$ & 400 & $(98.3)$ & 1,012 & (99.3) & 0.001 \\
\hline \multicolumn{8}{|l|}{ Treatment regimen } \\
\hline Surgery alone & 9 & $(1.5)$ & 103 & $(25.3)$ & 112 & $(11.0)$ & $<0.0001$ \\
\hline Chemotherapy + /- surgery & 210 & $(34.3)$ & 102 & $(25.1)$ & 312 & $(30.6)$ & 0.002 \\
\hline Radiation $+I-$ surgery & 3 & $(0.5)$ & 67 & $(16.5)$ & 70 & $(6.9)$ & $<0.0001$ \\
\hline $\begin{array}{l}\text { Chemotherapy and radiation }+/- \\
\text { surgery }\end{array}$ & 390 & $(63.7)$ & 135 & $(33.2)$ & 525 & $(51.5)$ & $<0.0001$ \\
\hline Anthracyclines received & & & & & & & $<0.0001$ \\
\hline Yes & 224 & $(36.6)$ & 93 & $(22.9)$ & 317 & $(31.1)$ & \\
\hline No & 388 & $(63.4)$ & 314 & $(77.1)$ & 702 & $(68.9)$ & \\
\hline Alkylating agents received & & & & & & & $<0.0001$ \\
\hline Yes & 46 & $(7.5)$ & 193 & $(47.4)$ & 239 & $(23.5)$ & \\
\hline No & 566 & $(92.5)$ & 214 & $(52.6)$ & 780 & $(76.5)$ & \\
\hline \multicolumn{8}{|l|}{ Radiation therapy site } \\
\hline Head or cranial & 0 & $(0.0)$ & 41 & $(10.1)$ & 41 & $(10.1)$ & $<0.0001$ \\
\hline Neck & 4 & $(0.7)$ & 30 & $(7.4)$ & 34 & $(3.3)$ & $<0.0001$ \\
\hline Chest & 134 & $(21.9)$ & 79 & (19.4) & 213 & $(20.9)$ & 0.15 \\
\hline Abdomen & 373 & $(60.9)$ & 113 & $(27.8)$ & 486 & $(47.7)$ & $<0.0001$ \\
\hline Spine & 0 & $(0.0)$ & 13 & $(3.2)$ & 13 & $(1.3)$ & $<0.0001$ \\
\hline Pelvis & 188 & $(30.7)$ & 64 & (15.7) & 252 & $(24.7)$ & $<0.001$ \\
\hline Limb & 0 & $(0.0)$ & 7 & $(1.7)$ & 7 & $(0.7)$ & 0.36 \\
\hline Total body & 0 & $(0.0)$ & 7 & (1.7) & 7 & $(0.7)$ & 0.36 \\
\hline \multicolumn{8}{|l|}{ Surgical procedures } \\
\hline Laminectomy & 0 & $(0.0)$ & 22 & $(5.4)$ & 22 & $(2.2)$ & $<0.0001$ \\
\hline Laparotomy & 170 & $(27.8)$ & 126 & (31.0) & 296 & $(29.0)$ & 0.15 \\
\hline Nephrectomy & 576 & (94.1) & 23 & $(5.7)$ & 599 & (58.8) & $<0.0001$ \\
\hline Thoracotomy & 16 & $(2.6)$ & 55 & $(13.5)$ & 71 & $(7.0)$ & $<0.0001$ \\
\hline Treatment era & & & & & & & 0.91 \\
\hline $1970-1979$ & 262 & $(42.8)$ & 210 & (51.6) & 472 & $(46.3)$ & \\
\hline $1980-1986$ & 350 & $(57.2)$ & 197 & (48.4) & 547 & (53.7) & \\
\hline
\end{tabular}

*Limited to those with complete treatment data; $* * P$-value reported for Chi-squared or Fisher exact test comparison of Wilms tumor versus

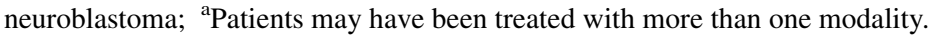

and neuroblastoma (mean $=42.41, \mathrm{SE}=2.23$ ) groups scored almost one standard deviation below the population mean of 50 ( $P<0.0001$ for both comparisons). Females (compared to males), Native Americans (compared to those who identified themselves as white), and those with an annual household income less than $\$ 20,000$ (compared to a household income greater than $\$ 100,000$ ) scored significantly lower on the MCS.
Table IV demonstrates the adjusted mean SF-36 subscale scores by diagnostic group and sociodemographic variables. As with the two summary scales, there were no differences between the Wilms tumor and neuroblastoma survivors on any of the eight subscales. Females scored significantly lower than males on all of the subscales except for bodily pain. Physical function scores were lower in those survivors who had not graduated from college, were looking for work or unable 
TABLE III. Adjusted Mean Scores on SF-36 Summary Scales

\begin{tabular}{|c|c|c|c|c|c|c|}
\hline & \multicolumn{3}{|c|}{ PCS } & \multicolumn{3}{|c|}{ MCS } \\
\hline & Mean $^{\mathrm{b}}$ & $\mathrm{SE}$ & $P$-value & Mean $^{b}$ & SE & $P$-value \\
\hline \multicolumn{7}{|l|}{ Diagnosis } \\
\hline Wilms ${ }^{\mathrm{a}}$ & 54.17 & 1.43 & & 41.66 & 2.19 & \\
\hline Neuroblastoma & 53.42 & 1.45 & 0.15 & 42.41 & 2.23 & 0.36 \\
\hline \multicolumn{7}{|l|}{ Age group } \\
\hline $18-24$ years & 55.92 & 1.44 & $<0.001$ & 41.74 & 2.21 & 0.36 \\
\hline $25-34$ years & 53.62 & 1.42 & 0.09 & 40.99 & 2.18 & 0.14 \\
\hline $35+$ years $^{\mathrm{a}}$ & 51.83 & 1.70 & & 43.37 & 2.60 & \\
\hline \multicolumn{7}{|l|}{ Gender } \\
\hline Male $^{\mathrm{a}}$ & 54.31 & 1.43 & & 43.79 & 2.20 & \\
\hline Female & 53.28 & 1.45 & 0.05 & 40.28 & 2.22 & $<0.001$ \\
\hline \multicolumn{7}{|l|}{ Race/ethnicity } \\
\hline White $^{\mathrm{a}}$ & 51.53 & 1.18 & & 46.24 & 1.81 & \\
\hline Native American & 55.01 & 3.60 & 0.31 & 31.34 & 5.52 & $<0.001$ \\
\hline Asian & 55.00 & 2.89 & 0.19 & 37.66 & 4.43 & 0.03 \\
\hline Black & 52.08 & 1.74 & 0.69 & 48.91 & 2.67 & 0.21 \\
\hline Hispanic & 51.48 & 1.76 & 0.97 & 48.69 & 2.70 & 0.26 \\
\hline Other & 57.66 & 3.45 & 0.08 & 39.38 & 5.29 & 0.20 \\
\hline \multicolumn{7}{|l|}{ Household income (annual) } \\
\hline$<\$ 20,000$ & 52.13 & 1.57 & 0.02 & 38.02 & 2.41 & $<0.001$ \\
\hline$\$ 20-59,999$ & 53.21 & 1.44 & 0.05 & 43.14 & 2.20 & 0.84 \\
\hline$\$ 60-99,000$ & 55.16 & 1.51 & 0.77 & 43.76 & 2.31 & 0.80 \\
\hline$\$ 100,000++^{\mathrm{a}}$ & 54.89 & 1.60 & & 43.40 & 2.45 & \\
\hline \multicolumn{7}{|l|}{ Education } \\
\hline$<$ High school & 51.95 & 1.84 & 0.05 & 40.15 & 2.81 & 0.09 \\
\hline High school graduate & 54.69 & 1.45 & $<0.001$ & 43.79 & 2.22 & 0.07 \\
\hline College graduate ${ }^{\mathrm{a}}$ & 52.93 & 1.38 & & 42.20 & 2.11 & \\
\hline \multicolumn{7}{|l|}{ Marital status } \\
\hline Married or living as married ${ }^{\mathrm{a}}$ & 52.43 & 1.49 & & 43.23 & 2.28 & \\
\hline Single & 51.93 & 1.52 & 0.42 & 43.72 & 2.32 & 0.61 \\
\hline Divorced or separated & 54.14 & 2.05 & 0.15 & 39.01 & 3.15 & 0.04 \\
\hline \multicolumn{7}{|l|}{ Employment } \\
\hline Employed or caring for home ${ }^{a}$ & 56.10 & 1.47 & & 42.92 & 2.25 & \\
\hline Looking for work or unable to work & 48.95 & 1.52 & $<0.001$ & 40.50 & 2.32 & 0.09 \\
\hline Student & 56.33 & 1.55 & 0.74 & 42.69 & 2.37 & 0.83 \\
\hline \multicolumn{7}{|l|}{ Health insurance } \\
\hline Yes $^{\mathrm{a}}$ & 54.87 & 1.54 & & 42.01 & 2.35 & \\
\hline No & 52.72 & 1.41 & 0.01 & 42.06 & 2.16 & 0.97 \\
\hline \multicolumn{7}{|l|}{ Major medical condition } \\
\hline $\mathrm{No}^{\mathrm{a}}$ & 54.53 & 1.39 & & 42.93 & 2.13 & \\
\hline Yes & 53.06 & 1.58 & 0.11 & 41.14 & 2.42 & 0.20 \\
\hline
\end{tabular}

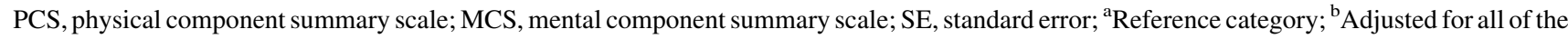
other variables in the model.

to work, had an annual household income less than $\$ 20,000$, did not have health insurance, or reported a major medical condition.

The results of the multiple variable models evaluating the association between diagnostic and treatment variables and poor outcome (score $<40$ ) on the summary scales or subscales of the SF36 are shown in Tables V and VI, stratified for the two diagnostic categories. In survivors of Wilms tumor (Table V), the final model included gender, age group at questionnaire, chest radiation, abdominal radiation, and pelvic radiation. After adjusting for the other variables in the model, no variable was associated significantly with a poor PCS score. However, females were more likely to have a poor MCS score than males $(\mathrm{OR}=1.67,95 \% \mathrm{CI}=1.1-2.5$, $P<0.05)$. Female gender was also associated with a significantly increased risk of a poor outcome on the general health $(\mathrm{OR}=2.13$,
$95 \% \mathrm{CI}=1.3-3.4, P<0.05)$, vitality $(\mathrm{OR}=1.89,95 \% \mathrm{CI}=1.3-$ 2.7, $P<0.05)$, and role function-emotional $(\mathrm{OR}=1.90,95 \%$ $\mathrm{CI}=1.3-2.8, P<0.05)$ subscales. Pelvic radiation was associated with poor outcome on the role function-physical subscale $(\mathrm{OR}=1.80,95 \% \mathrm{CI}=1.0-3.3, P<0.05)$.

In survivors of neuroblastoma (Table VI), the final model included gender, age at questionnaire, survival time, abdominal radiation, spinal radiation, pelvic radiation, and laminectomy. As with Wilms tumor, no variable was associated with a poor PCS score. Again, females were more likely to have a poor MCS score than males $(\mathrm{OR}=1.66,95 \% \mathrm{CI}=1.0-2.8, P<0.05)$. Female gender was also associated with a significantly increased risk of a poor outcome on the role function-physical $(\mathrm{OR}=2.07,95 \%$ $\mathrm{CI}=1.1-4.0, P<0.05)$, general health $(\mathrm{OR}=2.10,95 \% \mathrm{CI}=1.2-$ 
HRQL After Wilms Tumor or Neuroblastoma

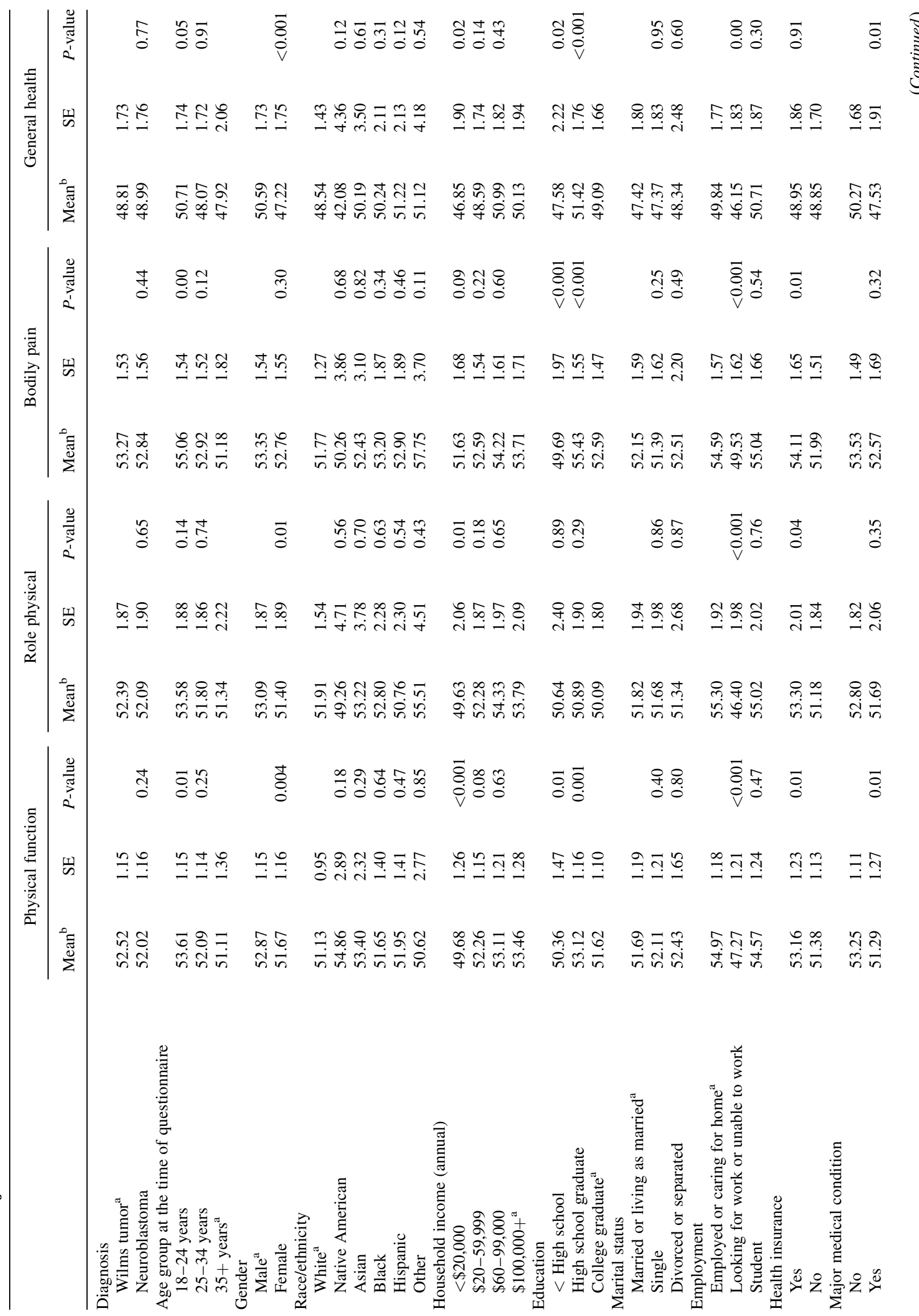


Nathan et al.

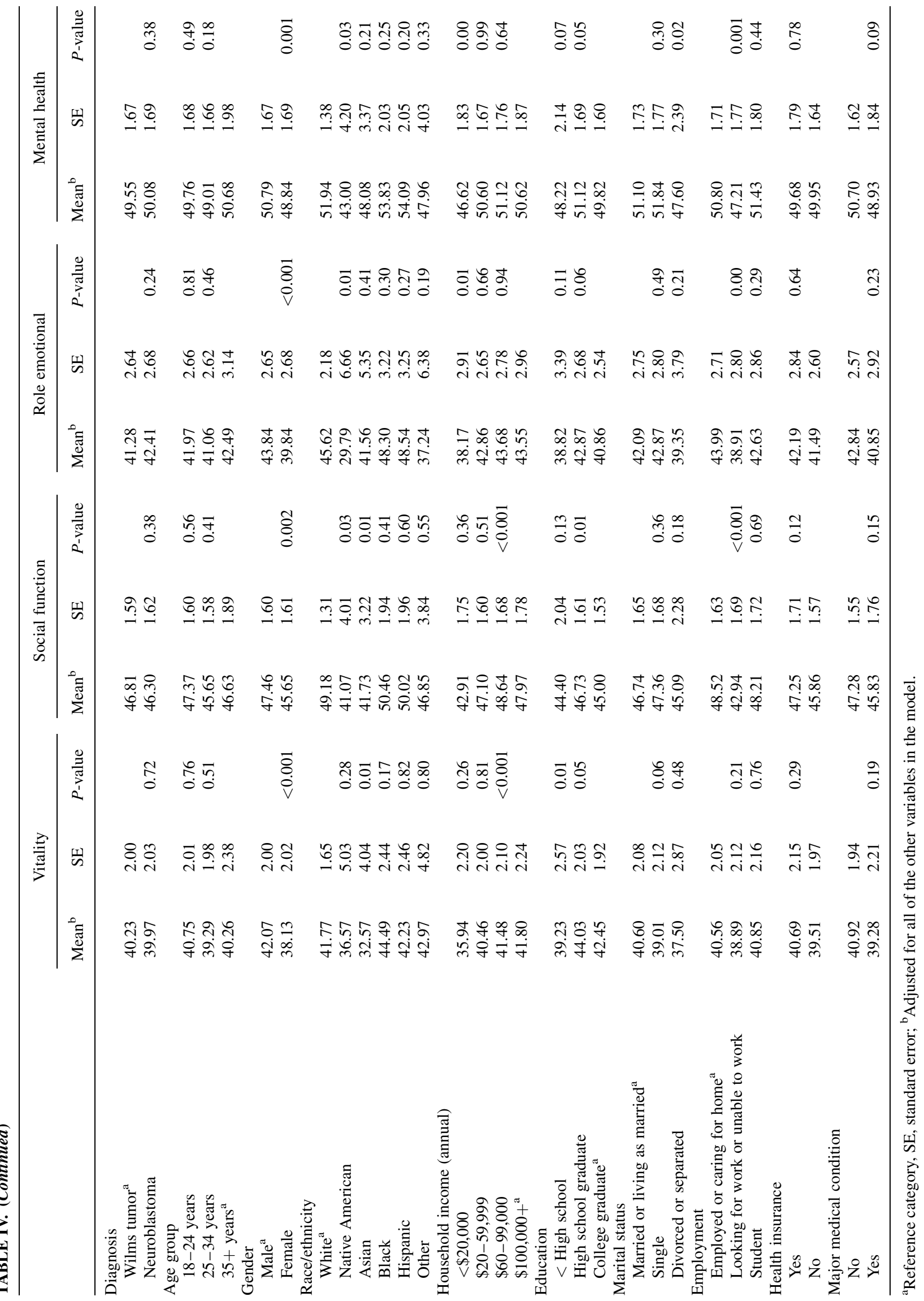




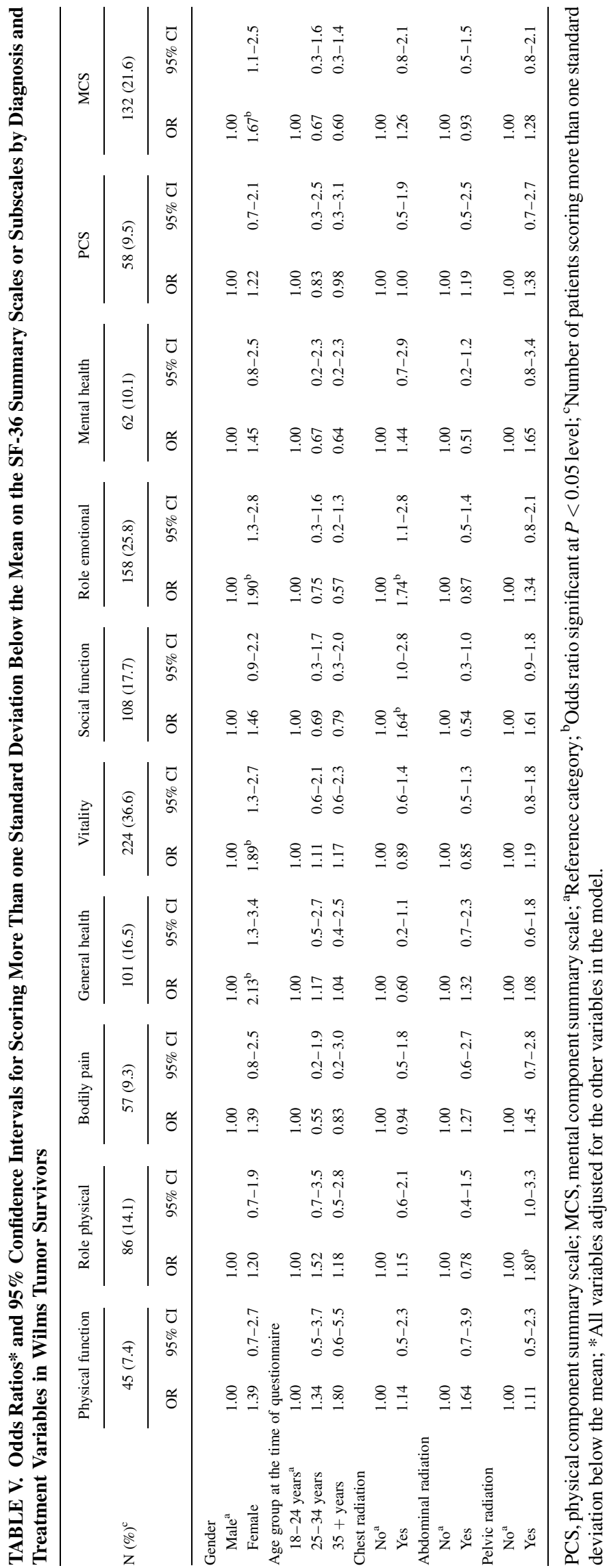




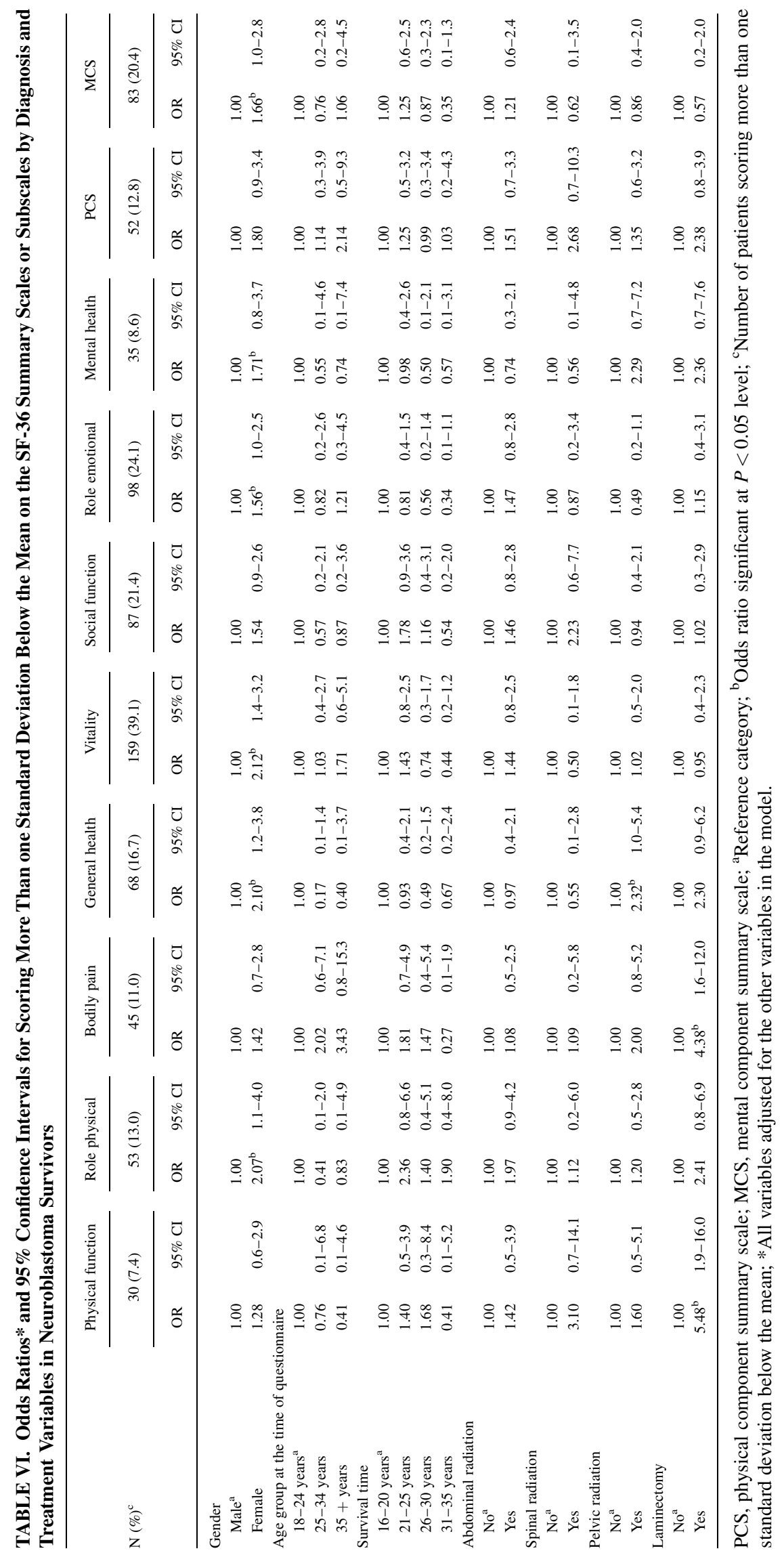


3.8, $P<0.05)$, vitality $(\mathrm{OR}=2.12,95 \% \mathrm{CI}=1.4-3.2, P<0.05)$, and role function-emotional $(\mathrm{OR}=1.56,95 \% \mathrm{CI}=1.0-2.5$, $P<0.05)$ subscales. Patients who received pelvic radiation demonstrated an increased risk of poor outcome on the general health subscale $(\mathrm{OR}=2.32,95 \% \mathrm{CI}=1.0-5.4, P<0.05)$. Patients who underwent a laminectomy had an increased risk of a poor outcome on the physical function $(\mathrm{OR}=5.48,95 \% \mathrm{CI}=1.9-16.0$, $P<0.05)$ and bodily pain $(\mathrm{OR}=4.38,95 \% \mathrm{CI}=1.6-12.0$, $P<0.05)$ subscales.

\section{DISCUSSION}

This follow-up study adds to the literature on health outcomes among long-term survivors of Wilms tumor and neuroblastoma by evaluating HRQL. In this population of young adults who were treated for cancer at a very young age, we found no evidence for significant deficits in HRQL measures representing physical well being or functioning. However, there is a clear pattern of poor emotional health evident in both diagnostic groups. Survivors scored considerably below population norms on the MCS scale of the SF-36, a composite measure reflecting performance on the vitality, social function, role-emotional, and mental health subscales. This is of particular concern because scores below 42 on this summary scale have been shown to have high sensitivity and specificity for diagnoses of depression in other studies [30]. Although women consistently scored lower than men on these measures, the pattern of lower scores was evident for both sexes. Poorer HRQL outcomes amongst females have been reported in many studies of both acute and chronic illness [31-33], and female survivors of childhood cancer have been demonstrated previously to have a higher likelihood of adverse health status [25] and poorer HRQL than males [34]. In addition to female gender, several other sociodemographic factors correlated with overall worse outcome on one or more measures of HRQL. These included patients who were unemployed or looking for work, those with lower annual incomes, and those who had not graduated from college. Importantly, no specific disease characteristics or treatment exposures were predictive of poorer performance on the MCS subscale for either diagnosis. Thus, treatment intensity is not predictive of poorer emotional health and all survivors should be evaluated for this adverse outcome regardless of the severity of their initial cancer. These findings may be important to primary care physicians, who are the most likely health care providers to have regular contact with this population and may be most able to screen for depression or anxiety during routine care visits.

We observed no difference on any measure of HRQL between diagnostic groups. This might be attributable to two factors. First, the survival of patients with high-risk neuroblastoma is poor [35], resulting in a relative absence of survivors of high-stage disease. Most survivors of high-risk neuroblastoma experience one or more long-term complications of their disease or therapy, with almost one third reporting severe or life-threatening complications [19]. The most common of these are hearing loss, hypothyroidism and acute ovarian failure. Although stage information was not captured in the CCSS database, over $40 \%$ of the neuroblastoma survivors in the current cohort did not receive any chemotherapy, suggesting a high proportion of patients with lower stage disease who are less likely to develop long-term adverse effects. Alternatively, the absence of a difference in HRQL between the two groups in this study may be explained by the historical use of more aggressive multi-modal therapies in many patients with Wilms tumor treated in prior eras. This might serve to increase their risk of long-term morbidity compared to contemporary cohorts. Almost two-thirds of Wilms tumor survivors in this cohort received radiotherapy and over one-third received anthracycline chemotherapy. These treatment modalities may increase the risk of the long-term sequelae of Wilms tumor therapy, including chronic renal failure [36], congestive heart failure [37], and second malignant neoplasms [7], all of which would have impact on HRQL.

As expected, both radiation and surgery for local control of the primary tumor impacted on HRQL. Survivors of Wilms tumor who had received pelvic radiation were more likely to perform poorly on the role function-physical subscale of the SF-36. Pelvic radiation in patients with Wilms tumor has been linked to premature ovarian failure, infertility, adverse pregnancy outcomes [38], and second malignant neoplasms [7]. Survivors of Wilms tumor who had received chest radiation were more likely to perform poorly on the social function and role function-emotional subscales of the SF-36. The use of chest radiation in Wilms tumor is usually reserved for patients with metastatic disease and this may reflect a group of survivors of higher risk disease. In survivors of neuroblastoma, a history of laminectomy was associated with an increased risk of poor performance on the role function-physical and bodily pain subscales of the SF-36. This might reflect the long-term consequences of this surgery which include scoliosis [19,39]. However, children requiring laminectomy are more likely to have presented with spinal cord compression and thus, their poor performance might reflect residual neurologic compromise [40]. In addition, pelvic radiation was linked to poor general health in this group of patients.

This study has some methodological limitations that should be considered when interpreting the results. First, although the SF-36 has been validated as a self-report instrument, data regarding current socioeconomic status and medical complications were generated similarly from self report, and were not validated externally. Second, incomplete participation in the CCSS by eligible patients may have biased our results if survivors with poorer HRQL were less (or more) likely to join the CCSS cohort and to continue to contribute information to the study. Although the response rate for the HRQL questionnaire was good amongst those survivors enrolled in the CCSS (75.4\%), non-respondents tended to be of lower socioeconomic status than participants and were somewhat more likely to have reported a major medical condition. These differences, not uncommon in health outcome studies, suggest caution be exercised when generalizing our findings to low social and economic strata. Third, the CCSS did not collect disease stage information because of a lack of consistency between staging systems used at different institutions. As a result, we cannot categorize survivors by disease stage, nor can we show the relationship between stage and HRQL outcomes. Finally, all members of this cohort were treated in the period between 1970 and 1986 and readers must be cautious in generalizing these results to patients treated on more contemporary protocols. Changes in the intensity of therapy, particularly in patients with Wilms tumor and those with low or intermediate risk neuroblastoma may result in different HRQL outcomes. Contemporary protocols often use lower doses of radiation and there have been improvements in the techniques and equipment used to deliver radiotherapy. There have been concomitant improvements in surgical techniques. Thus, patients treated on more recent protocols warrant separate investigation. 
Despite differences in therapy, long-term survivors of Wilms tumor and neuroblastoma do not differ in their assessment of HRQL. Their physical well being and functioning is comparable to population norms, but they score significantly below these norms on measures of emotional health. Women and survivors in lower sociodemographic strata demonstrate the greatest risk of adverse outcomes. Health care providers must be sensitive to the risk for adverse outcomes in these vulnerable groups and institute appropriate screening and intervention.

\section{ACKNOWLEDGMENT}

CCSS is supported by a grant from the National Cancer Institute (U24 CA55727) and by funds provided to the University of Minnesota Cancer Center by the Children's Cancer Research Fund. L.Z. is funded, in part, by a grant from the Lance Armstrong Foundation (G 00-12-076-02). M.G. holds the POGO Chair in Childhood Cancer Control at the University of Toronto.

\section{REFERENCES}

1. Cancer Incidence and Survival among Children and Adolescents: United States SEER Program 1975-1995. In: Ries LAG, Smith MA, Gurney JG, et al., editors. Bethesda, MD: National Cancer Institute; SEER Program; 1999.

2. Pizzo PA, Poplack DG. Principles and Practice of Pediatric Oncology. Philadelphia, PA: Lippincott Williams \& Wilkins; 2002.

3. Green DM, D'Angio GJ, Beckwith JB, et al. Wilms tumor. CA Cancer J Clin 1996;46:46-63.

4. Matthay KK, Villablanca J, Seeger RC, et al. Treatment of high-risk neuroblastoma with intensive chemotherapy, radiotherapy, autologous bone marrow transplantation, and 13-cis-retinoic acid. $\mathrm{N}$ Engl J Med 1999;341:1165-1173.

5. Weinstein JL, Katzenstein HM, Cohn SL. Advances in the diagnosis and treatment of neuroblastoma. Oncologist 2003;8: 278-292.

6. Sorensen K, Levitt G, Sebag-Montefiore D, et al. Cardiac function in Wilms tumor survivors. J Clin Oncol 1995;13:15461556.

7. Breslow NE, Takashima JR, Whitton JA, et al. Second malignant neoplasms following treatment for Wilm's tumor: A report from the National Wilms Tumor Study Group. J Clin Oncol 1995;13:18511859.

8. Green DM, Donckerwolcke R, Evans AE, et al. Late effects of treatment for Wilms tumor. Hematol Oncol Clin North Am 1995;9:1317-1327.

9. Egeler RM, Wolff JE, Anderson RA, et al. Long-term complications and post-treatment follow-up of patients with Wilms tumor. Semin Urol Oncol 1999;17:55-61.

10. Paulino AC, Wen BC, Brown CK, et al. Late effects in children treated with radiation therapy for Wilms tumor. Int $\mathrm{J}$ Radiat Oncol Biol Phys 2000;46:1239-1246.

11. Hogeboom CJ, Grosser SC, Guthrie KA, et al. Stature loss following treatment for Wilms tumor. Med Pediatr Oncol 2001; 36:295-304.

12. Willi SM, Cooke K, Goldwein J, et al. Growth in children after bone marrow transplantation for advanced neuroblastoma compared with growth after transplantation for leukemia or aplastic anemia. J Pediatr 1992;120:726-732.

13. Hovi L, Saarinen-Pihkala UM, Vettenranta K, et al. Growth in children with poor-risk neuroblastoma after regimens with or without total body irradiation in preparation for autologous bone marrow transplantation. Bone Marrow Transplant 1999;24:11311136.
14. Olshan JS, Willi SM, Gruccio D, et al. Growth hormone function and treatment following bone marrow transplant for neuroblastoma. Bone Marrow Transplant 1993;12:381-385.

15. Holtta P, Alaluusua S, Saarinen-Pihkala UM, et al. Long-term adverse effects on dentition in children with poor-risk neuroblastoma treated with high-dose chemotherapy and autologous stem cell transplantation with or without total body irradiation. Bone Marrow Transplant 2002;29:121-127.

16. Koyle MA, Hatch DA, Furness PD, 3rd, et al. Long-term urological complications in survivors younger than 15 months of advanced stage abdominal neuroblastoma. J Urol 2001;166:14551458.

17. van Santen HM, de Kraker J, van Eck BL, et al. High incidence of thyroid dysfunction despite prophylaxis with potassium iodide during (131)I-meta-iodobenzylguanidine treatment in children with neuroblastoma. Cancer 2002;94:2081-2089.

18. Weiss B, Vora A, Huberty J, et al. Secondary myelodysplastic syndrome and leukemia following 131I-metaiodobenzylguanidine therapy for relapsed neuroblastoma. J Pediatr Hematol Oncol 2003;25:543-547.

19. Laverdiere C, Cheung NK, Kushner BH, et al. Long-term complications in survivors of advanced stage neuroblastoma. Pediatr Blood Cancer 2005;45:324-332.

20. Barr RD, Chalmers D, De Pauw S, et al. Health-related quality of life in survivors of Wilms tumor and advanced neuroblastoma: A cross-sectional study. J Clin Oncol 2000;18:3280-3287.

21. Bertolini P, Lassalle M, Mercier G, et al. Platinum compoundrelated ototoxicity in children: Long-term follow-up reveals continuous worsening of hearing loss. J Pediatr Hematol Oncol 2004;26:649-655.

22. Simon T, Hero B, Dupuis W, et al. The incidence of hearing impairment after successful treatment of neuroblastoma. Klin Padiatr 2002;214:149-152.

23. Nathan PC, Furlong W, De Pauw S, et al. Health status of young children during therapy for advanced neuroblastoma. Pediatr Blood Cancer 2004;43:659-667.

24. Robison LL, Mertens AC, Boice JD, et al. Study design and cohort characteristics of the Childhood Cancer Survivor Study: A multiinstitutional collaborative project. Med Pediatr Oncol 2002;38: 229-239.

25. Hudson MM, Mertens AC, Yasui Y, et al. Health status of adult long-term survivors of childhood cancer: A report from the Childhood Cancer Survivor Study. Jama 2003;290:15831592.

26. Ware JE, Jr., Sherbourne CD. The MOS 36-item short-form health survey (SF-36). I. Conceptual framework and item selection. Med Care 1992;30:473-483.

27. McHorney CA, Kosinski M, Ware JE, Jr. Comparisons of the costs and quality of norms for the SF-36 health survey collected by mail versus telephone interview: Results from a national survey. Med Care 1994;32:551-567.

28. Khattree R, Naik DN. Multivariate data reduction and discrimination with SAS software. Cary, NC: SAS Institute; 2000.

29. Kleinbaum DG, Klein M. Logistic regression: A self learning text. New York, NY: Springer-Verlag; 2002.

30. Ware JE, Gandek B, Group IP. The SF-36 Health Survey: Development and use in mental health research and the IQOLA Project. I J Ment Health 1994;23:49-73.

31. Mrus JM, Williams PL, Tsevat J, et al. Gender differences in healthrelated quality of life in patients with HIV/AIDS. Qual Life Res 2005;14:479-491.

32. Holbrook TL, Hoyt DB, Stein MB, et al. Gender differences in long-term posttraumatic stress disorder outcomes after major trauma: Women are at higher risk of adverse outcomes than men. J Trauma 2002;53:882-888. 
33. Lindquist R, Dupuis G, Terrin ML, et al. Comparison of healthrelated quality-of-life outcomes of men and women after coronary artery bypass surgery through 1 year: Findings from the POST CABG Biobehavioral Study. Am Heart J 2003;146:10381044.

34. Langeveld NE, Grootenhuis MA, Voute PA, et al. Quality of life, self-esteem and worries in young adult survivors of childhood cancer. Psycho Oncol 2004;13:867-881.

35. Castleberry RP. Neuroblastoma. Eur J Cancer 1997;33:14301437.

36. Ritchey ML, Green DM, Thomas PR, et al. Renal failure in Wilms tumor patients: A report from the National Wilms Tumor Study Group. Med Pediatr Oncol 1996;26:75-80.
37. Green DM, Grigoriev YA, Nan B, et al. Congestive heart failure after treatment for Wilms tumor: A report from the National Wilms Tumor Study group. J Clin Oncol 2001;19:1926-1934.

38. Kalapurakal JA, Peterson S, Peabody EM, et al. Pregnancy outcomes after abdominal irradiation that included or excluded the pelvis in childhood Wilms tumor survivors: A report from the National Wilms Tumor Study. Int J Radiat Oncol Biol Phys 2004; 58:1364-1368.

39. Paulino AC, Fowler BZ. Risk factors for scoliosis in children with neuroblastoma. Int J Radiat Oncol Biol Phys 2005;61:865-869.

40. Hoover M, Bowman LC, Crawford SE, et al. Long-term outcome of patients with intraspinal neuroblastoma. Med Pediatr Oncol 1999;32:353-359. 